\title{
Comunicação e Gênero como área de pesquisa: características e desenvolvimento dos estudos a partir da análise bibliométrica
}

Communication and Gender as research area: characteristics and development of studies using a bibliometric analysis

Comunicación y Género como área de investigación: características y desarrollo de estudios a partir del análisis bibliométrico

DOI: https://doi.org/10.1590/1809-58442021305

\section{Camilla Quesada Tavares ${ }^{1}$}

http://orcid.org/0000-0001-5490-6850

Michele Goulart Massuchin ${ }^{2}$

http://orcid.org/0000-0001-7918-4487

Nayara Nascimento de Sousa ${ }^{1}$

https://orcid.org/0000-0002-9721-1685

Gabriela Almeida Silva ${ }^{1}$

https://orcid.org/0000-0003-2066-4499

${ }^{1}$ (Universidade Federal do Maranhão, Centro de Ciências Sociais, Saúde e Tecnologia, Programa de PósGraduação em Comunicação. Imperatriz - MA, Brasil).

${ }_{2}^{2}$ (Universidade Federal do Paraná, Setor de Comunicação, Artes e Design, Programa de Pós-Graduação em Comunicação. Curitiba - PR, Brasil).

\section{Resumo}

Este artigo tem por objetivo discutir as características e o desenvolvimento das pesquisas em Comunicação que fazem interface com os Estudos de Gênero. A pesquisa é feita tendo como base a verificação de trabalhos publicados em todas as edições de 70 revistas, classificadas com Qualis A1, A2, B1 e B2 na área da Comunicação e Informação, da Capes. A discussão dos dados tem como base aspectos relacionados a três eixos: áreas predominantes, métodos e técnicas empregadas e processos priorizados nas observações empíricas. Ao todo, foram encontrados 633 artigos que assumem a junção entre Comunicação e Gênero e que compõem o corpus deste trabalho. Os dados são apresentados a partir do método quantitativo, sendo que a análise das publicações foi feita com 
base na observação sistemática dos artigos, seguindo a técnica bibliométrica. Dentre os resultados, destacam-se as pesquisas qualitativas e nas subáreas do jornalismo e audiovisual.

Palavras-chave: Comunicação. Gênero. Produção Científica. Bibliometria. Artigos.

\begin{abstract}
This article aims to discuss the overview of characteristics and development of communication research that interface with gender analysis. The research is based on the analysis of articles published in 70 Brazilian scientific journals classified as A1, A2, B1 and B2 in the area of Communication and Information. The analysis presented is based on aspects related about three points: predominant areas, methods and techniques employed, and processes prioritized in empirical observations. The corpus or this article is formed by 633 articles about Communication and Gender found until 2019. The dates are presented from the quantitative method, and the analysis of the articles was made from the systematic observation of the publications, following the bibliometric technique. Among the results, we highlight the qualitative research and the sub-areas of journalism and audiovisual.
\end{abstract}

Keywords: Communication. Gender. Scientific Production. Bibliometrics. Articles.

\title{
Resumen
}

Este artículo tiene como objetivo discutir acerca de una visión general de las características y del desarrollo de la investigación en Comunicación que interactúan con el análisis de Género. Los estudios se basan en el análisis de artículos científicos publicados en 70 revistas clasificadas como A1, A2, B1 y B2 en el área de Comunicación e Información. El análisis presentado se basa en aspectos relacionados con tres ejes: áreas predominantes, métodos y técnicas empleados y procesos priorizados en observaciones empíricas. En total, fueron categorizados 633 artículos que asumen la unión entre Comunicación y Género y que constituyen el corpus de esta investigación. Los datos se presentan a partir del método cuantitativo, y el análisis de las publicaciones se basó en la observación sistemática de los artículos, siguiendo la técnica Bibliométrica. Entre los resultados, se destaca el predominio de la investigación cualitativa y las subáreas del periodismo y el audiovisual.

Palabras claves: Comunicación. Género. Producción Científica. Bibliometría. Artículos.

\section{Introdução}

A discussão sobre a problemática de gênero entrelaçada com a área da Comunicação, embora não seja recente, tem ganhado ênfase nas últimas duas décadas, especialmente pela ampliação da categoria de gênero nas análises, no aumento das pesquisas e espaços para que elas possam se desenvolver, tanto nos departamentos de comunicação e áreas afins, como nos programas de pós-graduação. Neste sentido, este artigo propõe uma investigação sobre o panorama das características e do desenvolvimento das pesquisas em Comunicação que fazem interface com análises de Gênero.

A finalidade é entender lacunas, avanços e questões que merecem maior atenção nos trabalhos posteriores. Esse tipo de estudo se torna importante quando se compreende 
a necessidade de descobrir hiatos presentes e encontrar estratégias para fechá-los (ESCOSTEGUY, 2018). Para viabilizar a pesquisa e compreendendo, ainda, a centralidade das publicações em artigos, os quais possuem maior potencial de divulgar resultados, o foco da catalogação se dá nas revistas da Comunicação e áreas afins, visto que "não há nenhum programa, ou linha de pesquisa de referência que trate exclusivamente dessa temática na Comunicação” (CORUJA, 2018, p. 153).

A pesquisa, portanto, é feita tendo como base a análise de artigos publicados em 70 revistas brasileiras classificadas com Qualis A1, A2, B1 e B2 na área da Comunicação e Informação da Coordenação de Aperfeiçoamento de Pessoal de Nível Superior (Capes). Após a verificação de todas as edições dos periódicos selecionados, foram encontrados 633 trabalhos que assumem a junção entre Comunicação e Gênero e que compõem o corpus desta pesquisa. Os dados são apresentados a partir do método quantitativo, sendo que a análise dos artigos foi feita de acordo com a observação sistemática, seguindo a técnica bibliométrica.

Mencionamos que o recorte considera a perspectiva de gênero de forma ampla. Portanto, os artigos discutem desde feminismo e pós-feminismo, até a perspectiva queer, masculinidades, transexualidade, homossexualidade, entre outras questões. Embora este trabalho não observe as diferentes categorias de gênero priorizadas nas pesquisas e como elas avançam longitudinalmente, Escosteguy (2018) evidencia que na última década tem havido ampliação dos focos de estudo.

A análise apresentada tem como base aspectos relacionados a três eixos, os quais são desenvolvidos na parte empírica do artigo: a) áreas predominantes, b) métodos e técnicas de pesquisa empregadas e c) processos priorizados nas observações empíricas. Antes da apresentação dos dados, discute-se, a seguir, a constituição da subárea da Comunicação e os estudos de Gênero, a partir de outros mapeamentos já realizados na área.

\section{Comunicação e Gênero como área de pesquisa: histórico e desenvolvimento no Brasil}

Para falar sobre a trajetória dos estudos de gênero, é importante entender que as pesquisas com esse foco nascem no bojo dos movimentos feministas, a partir da formação de grupos de estudos e reflexões na década de 1970, e intensificam-se em 1980, com o feminismo acadêmico (PINTO, 2003; MATOS, 2008; TOMAZETTI, 2019). A princípio, foram criados grupos formados por mulheres e, posteriormente, as pesquisas feministas e de gênero na academia se desenvolveram, possibilitando a elaboração de teorias que podem ser aplicadas em diversas áreas, inclusive na Comunicação (SCOFIELD, 2008).

A crítica ao uso do termo "mulher” se tornou mais enfática nos anos de 1970, na medida em que as mulheres que não faziam parte do círculo hegemônico (formado por brancas, intelectuais, classe média, heterossexuais) acabavam sendo invisibilizadas, como negras, pobres, lésbicas, trans e indígenas. Assim, a categoria “mulheres” passou a ser utilizada, a fim de respeitar as múltiplas diferenças que existiam dentro da diferença 
(PEDRO, 2005). Foi na década de 1980 que o uso do termo "gênero" se tornou consensual nas teorias e nos movimentos feministas. Com as transformações no entendimento conceitual do gênero, as pesquisas também acompanharam esse debate, inicialmente considerando a dualidade mulher-homem, depois partindo para a problematização entre mulheres-mulheres e homens-homens, até chegar em outras questões, como os LGBTs (PEDRO, 2005; MATOS, 2008).

Zirbel (2007) aponta que os primeiros estudos de gênero na academia geraram questionamentos quanto à legitimidade das pesquisas, porque uma parte da comunidade científica criticava a suposta falta de objetividade. Os trabalhos que tratavam de mulheres eram vistos como desviantes dos métodos científicos pelo fato de quebrarem uma heteronormatividade, em que se aceitava apenas a perspectiva masculinista. Assim "a ideia tradicional de ciência excluía desta o engajamento com o objeto de pesquisa ou algum tipo de posicionamento político, tornando o feminismo incompatível com a atividade científica” (ZIRBEL, 2007, p. 99).

O trabalho de Scott (1995) é fundamental para o embasamento das pesquisas interdisciplinares que utilizam o gênero como categoria de análise. Para a autora, o gênero é entendido como duas partes interligadas: "um elemento constitutivo de relações sociais baseadas nas diferenças percebidas entre os sexos e (...) uma forma primária de dar significado às relações de poder” (SCOTT, 1995, p. 86). Assim, a categoria gênero surgiu com o objetivo de distinguir e separar o sexo - no sentido biológico - do gênero - na dimensão histórica, social e política das relações (MATOS, 2008). Entretanto, a noção de que o sexo também se relaciona à construção social vai ganhando terreno nos anos 1990, especialmente com as contribuições de Butler (2003).

Em estudos mais recentes, Matos (2008) defende que o gênero não pode mais ser visto apenas como ferramenta analítica, mas como campo epistemológico das ciências, construindo uma teoria propriamente feminista. A autora faz críticas ao gênero como categoria de análise, considerando que a maior parte dos estudos se preocupa em abordar a forma binária para discutir a lógica das diferenças - homens e mulheres, masculino e feminino, homo e heterossexual.

Na área da Comunicação no Brasil, as pesquisas de gênero seguem a mesma linha de desenvolvimento. Tomazetti (2019, p. 163-164) identifica que elas nascem a partir da discussão sobre a condição feminina ainda na década de 1970, mas que isso não remete necessariamente a uma produção sobre estudos de gêneros. Isso porque, segundo o autor, “tematizar não significa propriamente refletir essa problemática”. Entre 1980 e 2010, houve um aumento entre as pesquisas de mestrado e doutorado da área que incorporaram teorias e conceitos de gênero nos trabalhos.

No entanto, apesar de virem ganhando espaço desde 2010, os estudos sobre gênero ainda são minoria dentro da área da Comunicação (ALMEIDA, 2018; CORUJA, 2018; TOMAZETTI, 2019). De acordo com o mapeamento realizado por Tomazetti (2019), 
entre 1972 e 2015 foram produzidos pouco mais de 13,2 mil trabalhos de mestrado e doutorado na área. Destes, apenas 316 apresentaram alguma interface com a perspectiva de gênero.

Na primeira década dos anos 2000, Escosteguy e Messa (2008) já haviam identificado a predominância dos estudos femininos e feministas entre aqueles que faziam a intersecção entre Comunicação e Gênero, algo também observado por Almeida (2018), Coruja (2018) e Tomazetti (2019). Coruja (2018) procurou entender como estavam problematizando o tema dentro da Comunicação e constatou que há disparidades relacionadas às regiões de publicação, sendo o Sudeste do país aquele que mais publica sobre. Outra constatação é que as mulheres lideram quando se trata de pesquisa com centralidade em feminismo, compondo $90 \%$ do contingente. Por meio de um estudo mais aprofundado das teses e dissertações produzidas, a autora também indica que há dificuldades em problematizar os conceitos (CORUJA, 2018).

Sarmento $(2013,2018)$ trabalha com a representação do feminismo na mídia, em interface com a internet e a política, e realiza uma revisão teórica para verificar como os movimentos feministas são visibilizados na mídia tradicional em diferentes marcos temporais e geográficos ocidentais (SARMENTO, 2018). A autora observa que os estudos buscam entender a representação feminina nos veículos comunicacionais, entretanto o ativismo feminino encontra impasses: normalmente a mulher é retratada no âmbito da feminilidade, como no caso de coberturas de candidatas; há também a demonização das feministas como forma de representação e a crítica ao pós-feminismo; o feminismo na mídia sofre com o chamado "ciclo de atenção", ou seja, é pertinente durante um tempo e depois cai no esquecimento (SARMENTO, 2018).

Apesar das pesquisas sobre feminismo se destacarem na subárea, houve um tímido crescimento daquelas destinadas às questões LGBTs e/ou queer, além de masculinidades. "As formulações de gênero desses estudos rompem com os limites da heterossexualidade, revelando as potencialidades do gênero para além do binarismo homem/mulher" (TOMAZETTI, 2019, p. 171). Tomazetti (2019) defende que entre 2001 e 2009 se realizaram as primeiras investigações que de fato problematizavam gênero, comunicação e sexualidade, ancoradas nos conceitos de representação e identidade. As pesquisas sobre transexualidade só aparecem a partir de 2013 nas teses e dissertações (TOMAZETTI, 2019). Por fim, tem-se os estudos sobre masculinidades, "preocupados com a reflexão das condições mutáveis dos ideais de masculinidades cujos parâmetros respondem a própria legitimação e conformação histórica do patriarcado” (TOMAZETTI, 2019, p. 47).

A constituição do campo e a identificação das principais pesquisas e lacunas da área só podem ser constatadas por meio de pesquisas bibliométricas e de mapeamento, como propomos também com este trabalho. A investigação sistematizada da produção serve para realizar micro e macroanálises, que se dedicam a compreender o desenvolvimento de um campo da ciência mais específico e/ou situar a produção, comparando um determinado país 
com aquilo que se publica no contexto global (MACIAS-CHAPULA, 1998, OLIVEIRA, 2019). Esta pesquisa, em particular, se enquadra no primeiro tipo, como veremos a seguir.

\section{Procedimentos metodológicos}

Para o desenvolvimento deste trabalho, foi realizado um mapeamento dos artigos publicados nas revistas de Qualis A1, A2, B1 e B2 da área da Comunicação e Informação, classificadas pela Coordenação de Aperfeiçoamento de Pessoal de Nível Superior (Capes) e editadas no Brasil. Como nem todos os periódicos dialogam com a subárea da Comunicação e Gênero, foram excluídos da análise aqueles sobre biblioteconomia e museologia, especialmente pela observação do escopo. Assim, ao todo, são 70 revistas que integram o corpus deste trabalho. Destaca-se que a maioria possui publicações semestrais e quadrimestrais e a escolha do Qualis se dá por conta do reconhecimento que tais estratos possuem, principalmente sendo foco dos Programas de Pós-Graduação, o que permite uma radiografia da referida área de estudos.

Para a catalogação dos artigos foi realizada uma minuciosa análise de cada edição dos referidos periódicos, considerando todas as publicações disponíveis nos acervos on-line durante o período da coleta ${ }^{1}$, realizado entre 2018 e 2019. Para selecionar os trabalhos que integram esta pesquisa, o critério utilizado foi conter as seguintes palavras-chaves nos títulos, resumos e/ou palavras-chaves: gênero, sexualidade, feminino(a), feminismo, masculinidades, termos que compõe ou a própria sigla LGBT+ e seus derivados, associados ao jornalismo e/ou comunicação e/ou mídia. Em alguns casos, termos correlatos foram adicionados por conta da leitura do resumo, que permitia a inclusão do texto no corpus da pesquisa. Esse levantamento, feito entre agosto de 2018 e junho de 2019, resultou na catalogação de 633 artigos publicados. É importante mencionar que se considerou a categoria gênero no sentido amplo, de forma que constituem o banco de dados os trabalhos que abordavam a perspectiva do feminino, masculino, homossexualidade, LGBTs, perspectiva queer, interseccionalidades, entre outras questões.

A categorização dos artigos foi feita pelo Grupo de Pesquisa Comunicação, Política e Sociedade (COPS), contando com o auxílio de cinco alunas de graduação e pósgraduação ${ }^{2}$. Todas passaram por um treinamento para a etapa de codificação dos dados ${ }^{3}$. Para a coleta das informações dos trabalhos, foi criado um livro de códigos com 35 variáveis, sendo que neste artigo são analisadas algumas que contemplam três eixos de discussão: áreas predominantes, métodos e técnicas empregados e processos priorizados nas observações empíricas.

\footnotetext{
1 Nesse sentido, não levou-se em consideração um recorte temporal específico das edições das revistas para a catalogação dos artigos, mas todas as publicações disponíveis nos acervos online até a última edição de 2018. Assim, há revistas mais antigas, que podem apresentar edições desde os anos de 1990, por exemplo, bem como outras editadas mais recentemente.

2 As autoras agradecem às alunas membros do grupo pelo trabalho coletivo realizado para a composição do banco de dados sobre a produção acadêmica da área.

3 O índice de confiabilidade entre as codificadoras resultou em mais de 80\% de acertos em todas as variáveis incluídas no artigo. 
Para discutir sobre as áreas predominantes, são analisadas as subáreas temáticas as quais pertencem os artigos dentro do campo da Comunicação e os objetos investigados, no caso das pesquisas empíricas. Em relação ao eixo denominado como métodos e técnicas empregados, tem-se a observação de quatro variáveis: natureza da pesquisa (se teórico ou empírico); métodos de pesquisa (quantitativo, qualitativo, bibliográfico ou misto) e abordagens metodológicas (dentre as principais elencadas na Comunicação somando-se à categoria “outros”). O último eixo busca analisar os processos comunicacionais priorizados nas observações empíricas com base no foco do trabalho.

Os procedimentos citados remetem à uma pesquisa de cunho quantitativo, que tem por objetivo identificar padrões (CERVI, 2009) na produção científica, tendo como base os pressupostos da técnica de análise de conteúdo (KRIPPENDORFF, 1990; BAUER, 2002), porém, verificando a produção científica, o que enquadra este artigo nos estudos bibliométricos. Dentre as distintas formas de levantamento de dados das revisões e mapeamentos, optou-se pelo uso da bibliometria como estratégia de sistematização das informações (DACOMBE, 2018) que, apesar de compor uma subárea da ciência da informação, tem caráter interdisciplinar e pode ser aplicada a outras áreas (MEDEIROS; VITORIANO, 2015). Destaca-se que os dados são expostos de modo agregado e de forma longitudinal, o que permite a observação das características, bem como sua evolução ao longo do tempo ${ }^{4}$.

\section{O que pesquisamos: subáreas predominantes nas pesquisas}

Os primeiros dados apresentados se referem às diferentes subáreas da Comunicação e mostram um desequilíbrio no desenvolvimento dos estudos que envolvem as relações de gênero. Foram considerados cinco subgrupos - Jornalismo; Cinema, Imagem e Audiovisualidades; Estudos de Mídia; Publicidade e Propaganda; e Relações Públicas e Comunicação Organizacional - somados a um grupo mais amplo denominado unicamente como Comunicação, especialmente para trabalhos de reflexão teórica ou de estudos que agrupassem mais de uma das demais categorias. A Tabela 1 indica que o Jornalismo (29,4\%) é a área que agrega mais trabalhos sobre Gênero, seguido de Cinema, Imagem e Audiovisualidades (28,3\%). Por outro lado, são poucos os trabalhos que discutem Gênero associado às Relações Públicas e Comunicação Organizacional (0,9\%) e Publicidade e Propaganda (7,7\%).

4 É importante mencionar que a pesquisa considerou sempre o arquivo on-line disponível pelas revistas. 
Tabela 1 - Subárea de pesquisa

\begin{tabular}{l|l|l}
\hline Subárea & Quantidade & Percentual \\
\hline Jornalismo & 186 & 29,4 \\
\hline Cinema, Imagem e Audiovisualidades & 179 & 28,3 \\
\hline Comunicação & 136 & 21,5 \\
\hline Estudo das Mídias & 77 & 12,2 \\
\hline Publicidade e Propaganda & 49 & 7,7 \\
\hline Relações Públicas e Com. & 6 & 0,9 \\
\hline Total & $\mathbf{6 3 3}$ & $\mathbf{1 0 0}$ \\
\hline
\end{tabular}

Fonte: autoras (2020).

O desequilíbrio bastante notável permite compreender lacunas nas quais é possível pensar uma análise a partir das categorias de Gênero. Sabe-se que as organizações têm feito um esforço para discutir inclusão e diversidade, investindo tanto em materiais publicitários, como em processos de relacionamento mais equitativos. Neste contexto, Andrade e Sobreira (2013) apontam que a área de Relações Públicas é construída majoritariamente por mulheres, porém, estas ocupações são de cunho técnico, o que pouco tem sido estudado no âmbito brasileiro e que pode abrir um leque de pesquisas.

Destaca-se, por outro lado, o avanço na área de Cinema e Audiovisual, com foco e atenção para a telenovela, o que pode ser resultado das discussões de gênero já previamente associadas aos Estudos Culturais (RONSINI; SILVA, 2011). Do mesmo modo, no caso do Jornalismo, o crescimento também é reflexo das preocupações do processo de representação de gênero em função da ligação direta com a formação da opinião pública. Além disso, a feminização das redações (ROCHA; WOITOWICZ, 2017), ocorrida nos anos 1970, também é um provável fator para reforçar pesquisas na área.

Apesar dessas distinções quantitativas na distribuição dos estudos de gênero dentro das subáreas, é importante reforçar o aumento das publicações ao longo do tempo, especialmente entre 2010 e 2018, último ano incluído na série temporal. Apesar do progresso, saindo de uma publicação catalogada em 1992, para 88 em 2018, também há diferenças no crescimento do interesse pela relação dentro de cada subárea. É importante destacar como fatores relevantes para a ampliação dos estudos o surgimento de grupos de pesquisas, linhas de pesquisa em programas de pós-graduação e a manutenção de publicações voltadas para discutir relações de gênero, assim como a publicação de dossiês nas revistas. O Gráfico 1, a seguir, mostra a distribuição longitudinal, separada pelas subáreas de pesquisa, sendo que o coeficiente de determinação $\left(\mathrm{r}^{2}\right)$ mostra quanto o tempo explica o crescimento das publicações de forma diferente para as áreas selecionadas na pesquisa. 
Gráfico 1 - Distribuição temporal do desenvolvimento das áreas (N=628)

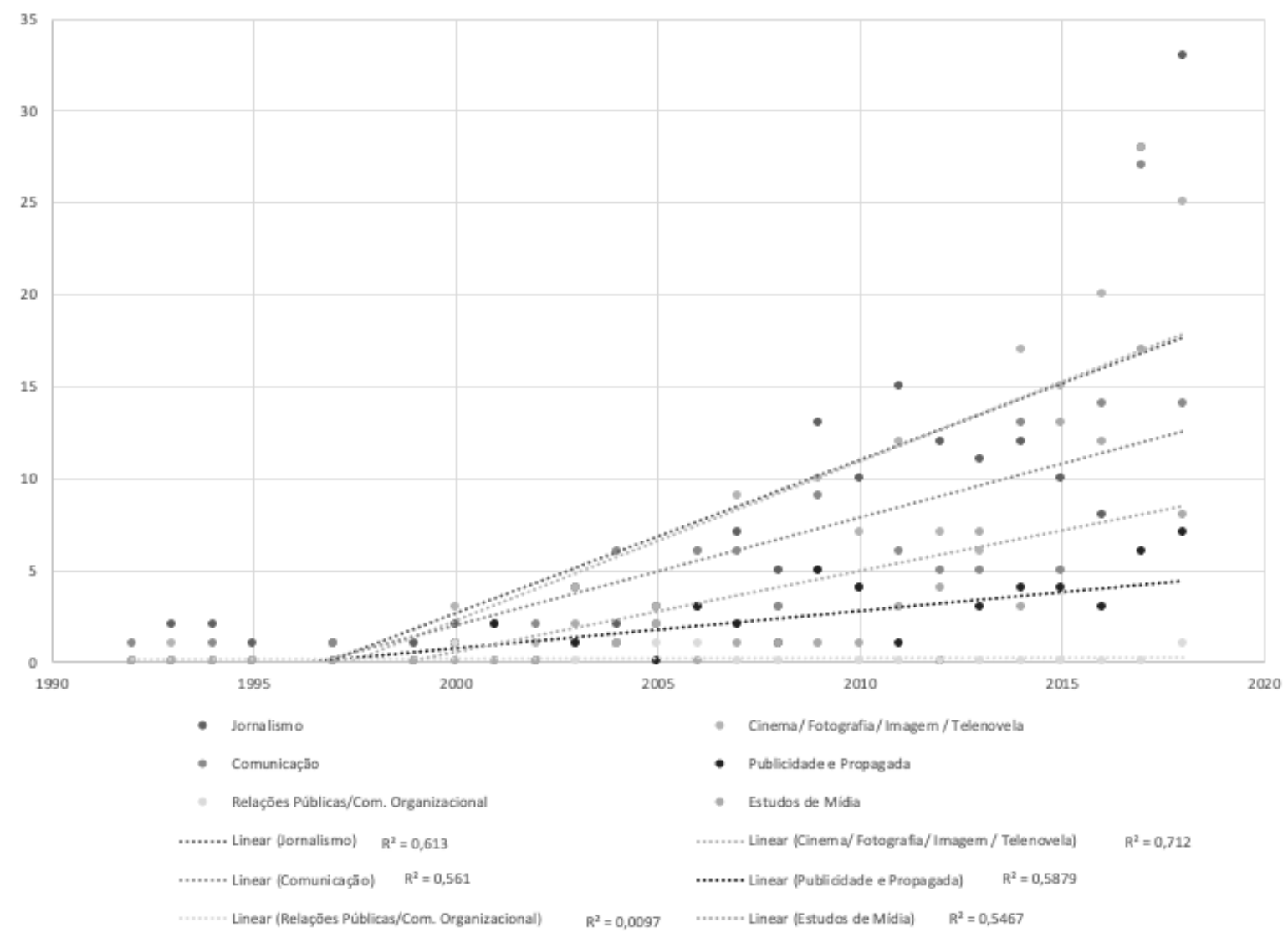

Fonte: autoras (2020).

Dentre as subáreas, a que mais se desenvolveu foi a de Cinema, Imagem e Audiovisualidades, sendo que o percentual de variação explicado pelo fator tempo foi de $71 \%\left(r^{2}=0,71\right)$. Muito próximo disso está o Jornalismo $\left(r^{2}=0,61\right)$. É importante mencionar que Publicidade e Propaganda, apesar de estar entre as áreas com menos estudos interseccionados com Gênero, foi uma das que mais cresceu $\left(r^{2}=0,58\right)$, especialmente a partir de 2009. Nos estudos de mídia - categoria na qual se encaixam novos produtos estudados, como videoclipes e quadrinhos - percebe-se um aumento importante, porém centrado nos anos após 2015. A única área que não apresenta crescimento e tem apenas trabalhos similares em diversos anos é Relações Públicas e Comunicação Organizacional, na qual se encontram as lacunas mais evidentes, dada a pouca atenção aos estudos que consideram aspectos de gênero relacionando às respectivas áreas, pelo menos no que tange às publicações nas revistas pesquisadas. 
Outra variável observada é o objeto de análise das pesquisas empíricas. Neste caso, são 572 artigos de natureza empírica e 61 trabalhos teóricos. Os dados, conforme a Tabela 2, mostram também um desequilíbrio nos objetos de maior interesse das pesquisas, com prioridade para jornais impressos e revistas (25,8\%) e cinema, séries, documentários e teatro (16,1\%). Esta preferência tem relação, claro, com as subáreas que mais apareceram acima. Porém, mesmo dentro daquelas subáreas, alguns objetos recebem menos atenção, como é o caso da mídia alternativa, do telejornal e do radiojornal. Destaca-se, por outro lado, as pesquisas com sites de notícias (4,6\%), ainda que estejam bem mais distantes do impresso e das revistas.

Tabela 2 - Tipo de objeto empírico predominante na pesquisa

\begin{tabular}{l|l|l}
\hline Objeto & Quantidade & Percentual \\
\hline Jornalismo Impresso/Revista & 163 & 25,8 \\
\hline Cinema/Séries/Documentários/Teatro & 102 & 16,1 \\
\hline Anúncio/Cam. Publicitária & 47 & 7,4 \\
\hline Mídias Sociais (Facebook, Twitter, Instagram) & 43 & 6,8 \\
\hline Ciberjornalismo (Site de Notícias) & 29 & 4,6 \\
\hline Audiência & 27 & 4,3 \\
\hline Fotografia & 25 & 3,9 \\
\hline Telenovela & 21 & 3,3 \\
\hline Entretenimento/Games & 19 & 3 \\
\hline Livros ou Literatura & 17 & 2,7 \\
\hline Internet (quando não define o espaço) & 15 & 2,4 \\
\hline Profissionais da Área & 14 & 2,2 \\
\hline Telejornal & 12 & 1,9 \\
\hline Blogs & 12 & 1,9 \\
\hline YouTube/Clipes/Música & 12 & 1,9 \\
\hline Radiojornal & 6 & 0,9 \\
\hline Espaços de Mídia Alternativa & 3 & 0,5 \\
\hline Outros & 3 & 0,5 \\
\hline Veículos Institucionais & 2 & 0,3 \\
\hline Total & $\mathbf{5 7 2}$ & $\mathbf{9 0 , 4}$ \\
\hline Sem objeto empírico & $\mathbf{6 1}$ & $\mathbf{9 , 6}$ \\
\hline & $\mathbf{6 3 3}$ & $\mathbf{1 0 0}$ \\
\hline
\end{tabular}

Fonte: autoras (2020). 
Corroborando com os achados de Sarmento (2018), internet e redes sociais aparecem com certa significância (2,4\% e 6,8\%, respectivamente), o que mostra um aumento da análise de práticas de comunicação e gênero, tal como o ativismo digital. É importante ressaltar que 7,4\% das pesquisas têm como objeto campanhas publicitárias, enquanto veículos institucionais foi a categoria menos presente e pode ser um eixo a ser estudado com mais ênfase. Outra questão bastante relevante de se observar é a adesão da intersecção entre entretenimento e estudos de gênero, pois telenovela, música, YouTube e entretenimento em geral (programas de auditório, games etc.) aparecem em 3,3\%, 1,9\% e 3\%, respectivamente, dos artigos analisados.

Dois outros pontos são ainda significativos. As pesquisas com foco na audiência, especialmente em decorrência da abordagem dos Estudos Culturais e à aderência aos estudos de gênero (ESCOSTEGUY; MESSA, 2008), têm destaque em 27 trabalhos, o que corrobora com os dados de Tomazzeti e Coruja (2017). Ressaltamos que embora estudos sobre audiência apresentem uma abordagem teórico-metodológica própria, aqui considerouse que o foco dos estudos eram a audiência (ouvintes, telespectadores, seguidores etc.), em oposição aos produtores que estão por detrás dos conteúdos midiáticos, por exemplo. De outro modo, chama a atenção a pouca reflexão feita com base nos estudos de gênero para observar os produtores de conteúdo, seja de notícias ou de produtos audiovisuais, sendo que os reflexos das relações no ambiente de trabalho podem traduzir-se em produções midiáticas carregadas de estereótipos e invisibilidades (BIROLI, 2010).

\section{Como observamos: métodos e técnicas predominantes}

Neste tópico, discute-se como são feitas as pesquisas e a partir de quais estratégias metodológicas são observados os objetos elencados acima. Assim, a Tabela 3 diz respeito à natureza da pesquisa realizada, se teórica ou empírica. Os dados mostram que há predomínio de pesquisas empíricas (90\%) ante às pesquisas teóricas (10\%), o que vai ao encontro de outros estudos já realizados que indicam cenário similar (DOW; CONDIT, 2005).

Tabela 3 - Natureza da pesquisa desenvolvida

\begin{tabular}{l|l|l}
\hline Tipo de Pesquisa & Quantidade & Percentual \\
\hline Teórica & 61 & 10 \\
\hline Empírica & 572 & 90 \\
\hline Total & $\mathbf{6 3 3}$ & $\mathbf{1 0 0}$ \\
\hline
\end{tabular}

Fonte: autoras (2020).

Se por um lado as pesquisas empíricas apontam o avanço da área, as teóricas revelam a produção de novas teorias, o que também é relevante para a não estagnação, já que a ausência 
de reflexões teóricas pode demonstrar dificuldade no desenvolvimento de novas teorias (DOW; CONDIT, 2005). Neste sentido, apesar da dificuldade dos estudos em apresentarem novidades do ponto de vista teórico, percebe-se uma maior conexão das pesquisas com a realidade social, já que as discussões teóricas são checadas com a observação da produção, do conteúdo ou da recepção, no caso da interface com a Comunicação. Vale mencionar, ainda, que as pesquisas empíricas apresentam reflexões teóricas que embasam a investigação e fornecem elementos para a análise dos resultados encontrados, podendo contribuir também com a prospecção de novas abordagens teóricas.

De forma complementar, o Gráfico 2 apresenta a distribuição longitudinal das pesquisas, mostrando que as empíricas, de fato, foram as responsáveis pelo avanço dos estudos sobre Comunicação e Gênero. O gráfico reforça que esse crescimento se dá especialmente a partir do ano 2002, ainda que tenha havido algumas oscilações posteriores.

Gráfico 2 - Distribuição temporal dos estudos teóricos e empíricos

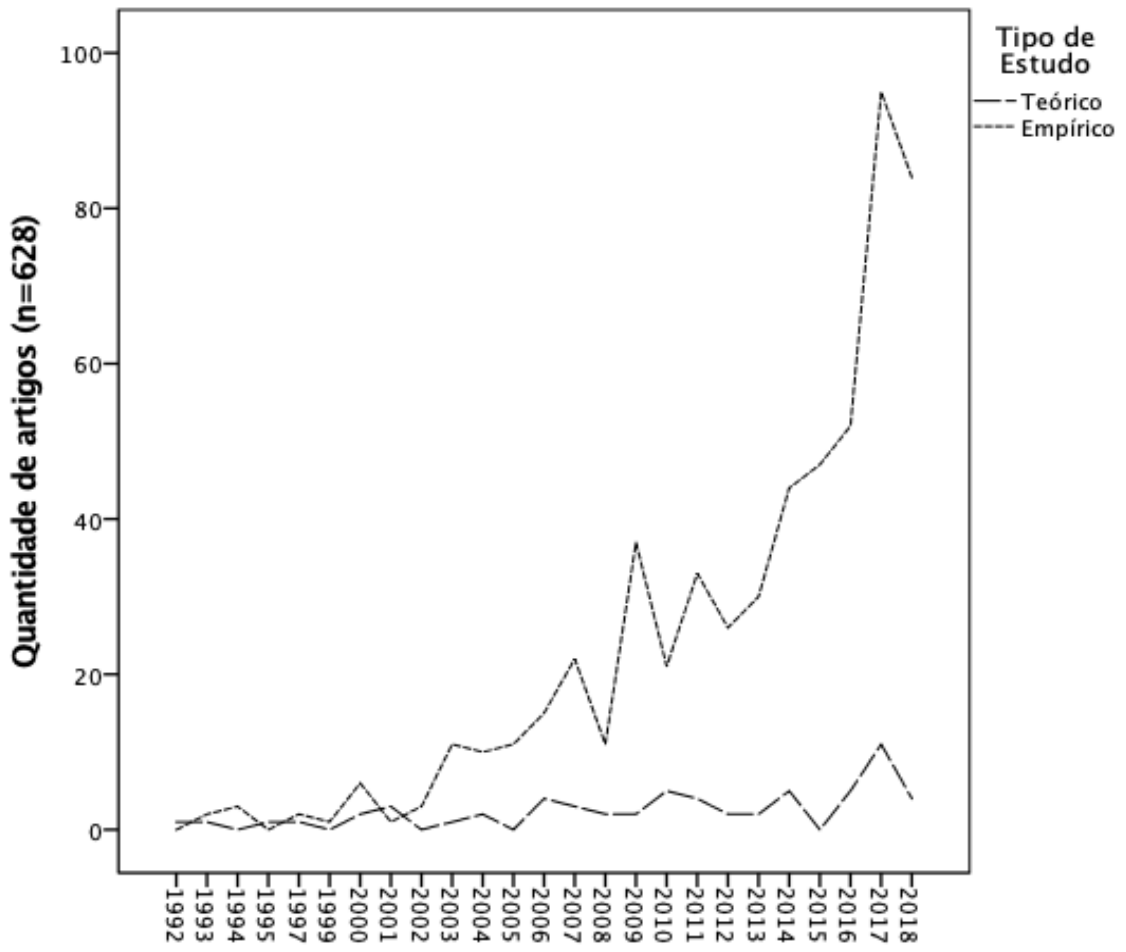

Ano de Publicação

Fonte: autoras (2020).

Apesar do leve aumento das publicações de pesquisas teóricas em alguns momentos, especialmente em anos como 2010, 2016, 2017 e 2018, há poucas mudanças se comparado às 
pesquisas empíricas. É importante mencionar, antes de finalizar esta discussão, que muitas revistas tendem a aceitar mais estudos empíricos, o que pode se refletir nos resultados, já que este trabalho tem como escopo de análise somente artigos de revistas. De toda forma, seguindo a proposição de Dow e Condit (2005), o ideal para as áreas seria o equilíbrio, demonstrando que pesquisas empíricas geram, além de resultados pontuais, um conjunto de questões que permite o desenho de novas teorias.

Além do tipo de pesquisa, observou-se o método utilizado, tendo como base a divisão entre as abordagens quantitativas e qualitativas, somando-se à bibliográfica para os casos de estudos de cunho teórico. Com o avanço das pesquisas e da proposição da triangulação metodológica (FIGARO, 2014), também foi adicionada uma quarta categoria para dar conta de trabalhos que demonstram o viés quanti/qualitativo. No geral, observando a Tabela 4, tem-se majoritariamente pesquisas baseadas no método qualitativo (79\%) na área de Comunicação e Gênero, seguidas do bibliográfico - no qual foram enquadrados os estudos teóricos. O método quantitativo foi o que menos apareceu, representando apenas 3,9\% dos trabalhos. A abordagem múltipla, com técnicas pertencentes ao quantitativo ou qualitativo, chega a 7,4\%.

Tabela 4 - Tipo de método de pesquisa utilizado

\begin{tabular}{l|l|l}
\hline Método & Quantidade & Percentual \\
\hline Qualitativo & 500 & 79 \\
\hline Bibliográfico & 61 & 9,6 \\
\hline Quanti/Quali & 47 & 7,4 \\
\hline Quantitativo & 25 & 3,9 \\
\hline Total & $\mathbf{6 3 3}$ & $\mathbf{1 0 0}$ \\
\hline
\end{tabular}

Fonte: autoras (2020).

Vale destacar que nenhum método tem prioridade em detrimento do outro no que tange a juízos de valor (CERVI, 2009). No entanto, se por um lado é importante uma observação detalhada e aprofundada sobre os objetos - sejam eles produtores, receptores ou os próprios conteúdos - o que traria uma análise minuciosa dos casos a partir do estudo qualitativo, também é importante que haja observações que permitam algum tipo de generalização dos resultados, o que seria de responsabilidade da metodologia quantitativa.

Outra característica analisada nos artigos incluídos no corpus deste mapeamento diz respeito às abordagens/técnicas utilizadas para alcançar os objetos das pesquisas empíricas. Foram enquadrados como "não se aplica” os trabalhos de caráter teórico ou de mapeamento da área ${ }^{5}$. A principal técnica utilizada foi a análise de conteúdo, em 46,6\% das publicações, seguida da análise do discurso (18,3\%). Estes dados já induzem para o foco na análise de

5 Destaca-se que alguns trabalhos apresentavam mais de uma técnica de pesquisa. Neste caso, considerou-se a técnica principal citada no artigo ou aquela que usava maior espaço na apresentação da parte empírica. No entanto, ressalta-se que mais de uma técnica só apareceu em $21 \%$ dos artigos. 
produtos e conteúdos, sejam eles jornalísticos ou de entretenimento, o que será discutido mais adiante neste artigo. Somente na sequência, como a terceira técnica mais usada, aparece a entrevista, com 5,1\%.

Chama a atenção que 9,8\% dos trabalhos apresentam outras abordagens de pesquisa, diferentes daquelas comumente citadas nos livros de metodologia em Comunicação, o que demonstra, de certo modo, uma tentativa de buscar novas formas de olhar para distintos objetos da área. Alguns exemplos são a análise de imagem a partir da teoria da montagem; análise textual pela teoria da argumentação, dentre outros. Por outro lado, observa-se a utilização irrisória de algumas técnicas/abordagens, o que pode ter relação com a baixa presença de certos objetos - como produtores e audiência. É o caso da etnografia, da observação participante, do survey, do grupo focal e da história oral.

Tabela 5 - Abordagens/técnicas utilizadas nos artigos

\begin{tabular}{l|l|l}
\hline Técnica de Pesquisa & Frequência & Percentual \\
\hline Análise de Conteúdo & 295 & 46,6 \\
\hline Análise de Discurso & 116 & 18,3 \\
\hline Outra & 62 & 9,8 \\
\hline Entrevista & 32 & 5,1 \\
\hline Semiótica & 16 & 2,5 \\
\hline Estudo de Caso & 14 & 2,2 \\
\hline Etnografia & 14 & 2,2 \\
\hline Observação Participante/Pesquisa Ação & 10 & 1,6 \\
\hline Grupo de Discussão & 4 & 0,6 \\
\hline Questionário/Survey & 3 & 0,5 \\
\hline Grupo Focal & 3 & 0,5 \\
\hline Análise de Redes & 2 & 0,3 \\
\hline História Oral & 1 & 0,2 \\
\hline Não se aplica & 61 & 9,6 \\
\hline Total & $\mathbf{6 3 3}$ & $\mathbf{1 0 0}$ \\
\hline
\end{tabular}

Fonte: autoras (2020).

Sobre a escassa presença do uso de algumas técnicas citadas, é importante mencionar as dificuldades do trabalho de campo, de chegar ao objeto, seja ele composto de produtores ou de receptores ${ }^{6}$. Em contrapartida, diferente das técnicas de pesquisas já consolidadas que pouco aparecem, a análise de redes, mais recentemente usada na área, já apareceu em

6 Menciona-se que a catalogação considerou a abordagem/técnica citada pelo autor ou autora, não fazendo uma análise da execução e desenvolvimento de cada técnica, não sendo verificado, por exemplo, o prosseguimento dos protocolos de pesquisa, se foram ou não adequados. 
dois artigos sobre Comunicação e Gênero. Como a escolha das técnicas e métodos estão alinhadas aos objetivos da pesquisa, isso resulta na observação e priorização de algumas etapas do processo comunicacional ante outras, como mostra o tópico seguinte.

\section{Que aspectos priorizamos: processos nas observações empíricas}

Nesta última parte de discussão dos dados, busca-se verificar como alguns tipos de análise acabam sendo mais comuns, especialmente em função das técnicas de pesquisas que já se mostraram predominantes. No geral, este tópico apresenta as características mais qualitativas dos artigos catalogados, considerando o que foi priorizado pelos autores e autoras em termos de análise. Para isso, é observada a etapa do processo comunicacional - se o foco estava na produção, conteúdo ou recepção.

Os dados da Tabela 6 mostram que há uma prioridade dos desenhos de pesquisa pelo foco no conteúdo publicado nos mais variados suportes, desde jornalísticos até fílmicos (71,1\%). Na sequência, está a preferência na recepção ou no comportamento do público, que aparece em 13\% dos artigos. Neste caso, os trabalhos analisam como questões de gênero interferem no modo como a audiência consome e interpreta os conteúdos.

Tabela 6 - Etapa do processo comunicacional priorizada nas pesquisas

\begin{tabular}{l|l|l}
\hline Etapa do Processo Comunicacional & Frequência & Percentual \\
\hline Processo de produção & 40 & 6,3 \\
\hline Conteúdo de mídia nos suportes & 450 & 71,1 \\
\hline Recepção/Comportamento do Público & 82 & 13 \\
\hline Não se aplica & 61 & 9,6 \\
\hline Total & $\mathbf{6 3 3}$ & $\mathbf{1 0 0}$ \\
\hline
\end{tabular}

Fonte: autoras (2020).

O que menos tem ganhado foco nas pesquisas e apresenta-se como uma lacuna ainda a ser desenvolvida são os trabalhos que observam o processo de produção e como o gênero pode ser uma variável que interfere no modo como trabalham, se relacionam e se constroem os produtos comunicacionais ${ }^{7}$. Este tipo de pesquisa aparece em somente 6,3\% das publicações. Outro dado relevante é obtido pela série temporal que, novamente, apresenta um ponto de inflexão nas pesquisas, datado do início do século XX, como pode ser percebido no Gráfico 3.

7 Os casos dos artigos teóricos foram desconsiderados na distribuição, já que o foco era nos trabalhos empíricos e o modo como se relacionavam com a realidade social. 
Gráfico 3 - Distribuição temporal dos processos priorizados

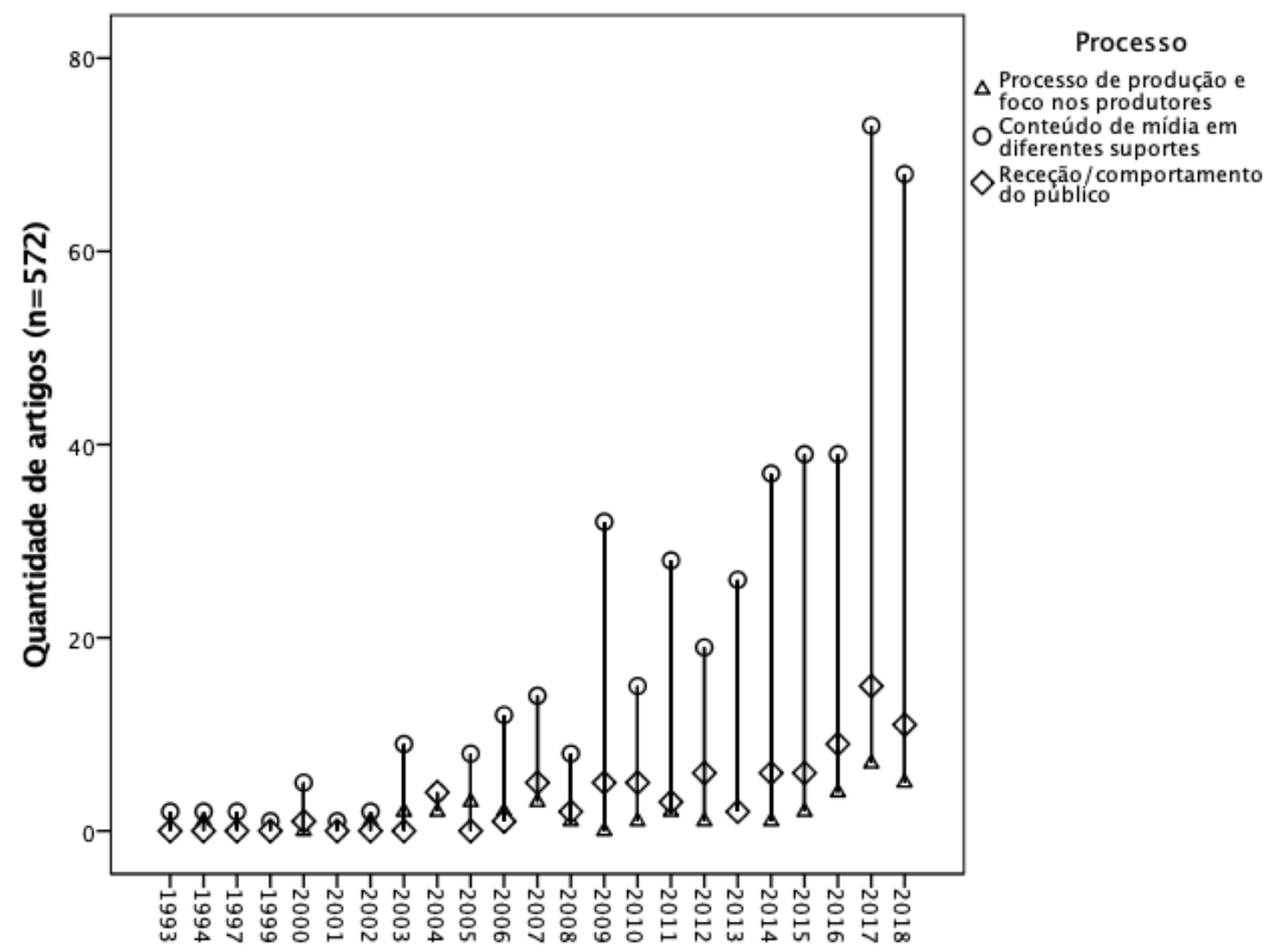

\section{Ano de Publicação}

Fonte: autoras (2020).

O Gráfico 3 permite identificar que apesar do avanço das pesquisas no século XXI, o que se desenvolveu, de fato, foram os trabalhos com foco no conteúdo, sendo isso que representa boa parte do aumento das pesquisas na área. A lacuna dos trabalhos que olham para as pontas do processo - produção e recepção - só começa a ser sanada a partir de 2010, mas com um crescimento mais considerável a partir de 2016, especialmente para as pesquisas que olham para a recepção. As investigações sobre o processo de produção foram as que ganharam espaço mais tardiamente nos artigos publicados nas revistas brasileiras, com maior densidade também desde 2015, mas basicamente inexistentes na década de 1990. Assim, após todos os problemas identificados nos produtos comunicacionais, é preciso entender - essencialmente - aquilo que está por trás da produção. 


\section{Considerações finais}

O mapeamento apresentado neste trabalho oferece um panorama sobre as pesquisas existentes sobre Comunicação e Gênero no Brasil, com base nas publicações qualificadas na área. Considerando os dados apresentados, identificamos grandes avanços de modo longitudinal, especialmente a partir de 2010. As principais áreas da Comunicação em que os estudos sobre gênero têm se mostrado uma preocupação são o Jornalismo e Cinema e Audiovisual, enquanto na Publicidade e Propaganda e Relações Públicas eles ainda são incipientes e podem ganhar mais destaque em trabalhos futuros.

Jornais impressos, revistas e audiovisualidades são os objetos mais estudados. Outros, como os profissionais da Comunicação, telenovelas, telejornais, radiojornais, blogs e audiência foram pouco explorados a partir da perspectiva de gênero. Pesquisas que observam quadrinhos e videoclipes têm surgido desde 2015, mas, de modo geral, constatase muitas lacunas ainda a serem preenchidas no que tange aos objetos analisados. Sobre os recursos metodológicos, a grande maioria dos trabalhos publicados é de abordagem empírica e qualitativa, tendo a análise de conteúdo como principal técnica adotada, seguida da análise do discurso.

Entre os processos que recebem mais enfoque nas pesquisas, o conteúdo das mídias é priorizado. Por outro lado, há irrisórios estudos sobre o processo de produção abordando a perspectiva de gênero. Isso significa que a produção acadêmica sobre Comunicação e Gênero, no Brasil, é focada no Jornalismo e Cinema, analisando o conteúdo dos jornais impressos ou da produção audiovisual. São poucos os estudos de recepção - que começaram a ser publicados em 2010 - e no âmbito da produção, assim como pesquisas que adotam o método quantitativo ou misto. Ou seja, existem diversos caminhos ainda a serem explorados, como, por exemplo, compreender como o gênero pode ser uma variável que interfere no modo como os profissionais da área atuam, especialmente relações públicas, publicitários e comunicadores institucionais; ou entender os processos e as relações internas das mídias, além de explicar o porquê de os conteúdos comunicacionais serem como são.

Destacamos, ainda, questões adicionais que carecem de reflexão, mas que não fizeram parte deste artigo. O texto, por exemplo, não aborda as distintas categorias de gênero para entender as multiplicidades de estudos e a ampliação do próprio conceito. Da mesma forma, não foi trabalhada a perspectiva teórica abordada nas publicações, o que traria complexidade para a discussão, à medida que permite entender até que ponto o gênero se coloca do ponto de vista teórico, realmente demonstrando uma intersecção entre as áreas, ou é apenas uma variável pontual trazida para o desenho metodológico, sem uma real problematização dos resultados apresentados.

Ainda que haja lacunas - seja neste texto ou na própria área - o que reforça a necessidade de seguir trabalhando nesta interseção entre fenômenos e processos comunicacionais e as relações de gênero, não há como deixar de apontar a relevância 
da multiplicidade das pesquisas, pois é através dessa amplitude de temas, de novos questionamentos, objetos, métodos e processos que se torna possível o desenvolvimento da área. Espera-se, por fim, que o mapeamento apresentado incentive pesquisas futuras a sanar, pelo menos em partes, os gaps existentes entre os estudos sobre Comunicação e Gênero no país, muitos deles apontados neste texto, mas outros também evidenciados por demais trabalhos já publicados.

\section{Referências}

ALMEIDA, G. C. C. A mulher na pesquisa em jornalismo teses e dissertações defendidas em Programa de Pós-Graduação em Jornalismo e Comunicação do Brasil (1972-2015). Dissertação (Mestrado em Jornalismo), Universidade Estadual de Ponta Grossa, 2018. 149 f.

ANDRADE, C; SOBREIRA, R. Igualdade de género na profissão de relações públicas: estudo exploratório com estudantes de comunicação organizacional. Exdra, n. 7, p. 41-50, 2013.

BAUER, M. W. Análise de conteúdo clássica: uma revisão. In: BAUER, M. W.; GASKELL, G. Pesquisa qualitativa com texto, imagem e som: um manual prático I. Tradução: Pedrinho A. Guareschi. 2a. ed. Petrópolis: Vozes, p. 189-217, 2002.

BIROLI, F. Gênero e política no noticiário das revistas semanais brasileiras: ausências e estereótipos. Cadernos Pagu, n. 34, p. 269-299, 2010.

BUTLER, J. Problemas de gênero: feminismo e subversão da identidade. Tradução: Renato Aguiar. Rio de Janeiro: Editora Civilização Brasileira, 2003.

CERVI, E. U. Métodos quantitativos nas ciências sociais: uma abordagem alternativa ao fetichismo dos números e ao debate com qualitativistas. In: J. A. BOURGUIGNON (org.). Pesquisa Social: reflexões teóricas e metodológicas. Ponta Grossa: Toda Palavra, p. 125-143, 2009.

CORUJA, P. Comunicação e Feminismo: um panorama a partir da produção de teses e dissertações do campo da Comunicação entre 2010 e 2015. Ártemis, Paraíba, v. 25, n. 1, p. 148-162, jan./jun. 2018.

DACOMBE, R. Systematic Reviews in Political Science: What Can the Approach Contribute to Political Research? Political Studies Review, v. 16, n. 2, p. 148-157, 2018.

DOW, B.; CONDIT, C. M. The State of the Art in Feminist Scholarship in Communication. Journal of Communication, v. 55, p. 448-478, 2005.

ESCOSTEGUY, A. C. D. Apontamentos sobre a formação de uma crítica feminista de mídia no Brasil. In: BIANCHI, G. S.; WOITOWICZ, K. J.; ROCHA, Paula M. (org.). Gênero, mídia \& lutas sociais: percepções críticas e experiências emancipatórias. Ponta Grossa: UEPG, p. 11-27, 2018.

ESCOSTEGUY, A. C. D.; MESSA, M. R. Os estudos de gênero na pesquisa em Comunicação no Brasil. In: ESCOSTEGUY, A. C. D. (org.). Comunicação e Gênero: a aventura da pesquisa. Porto Alegre: EDIPUCRS, p. 14-29, 2008.

FIGARO, R. A triangulação metodológica em pesquisas sobre a comunicação no mundo do trabalho. Revista Fronteiras, v. 16, n. 2, p. 124-131, 2014.

KRIPPENDORFF, K. Metodologia de análisis de contenido: teoría y práctica. Barcelona: Paidós, 1990. 
MATOS, M. Teorias de gênero ou teorias e gênero? Se e como os estudos de gênero e feministas se transformaram em um campo novo para as ciências. Estudos Feministas, Florianópolis, v. 16, n. 2, p. 333357, maio/ago. 2008.

MACIAS-CHAPULA, C. A. O papel da informetria e da cienciometria e sua perspectiva nacional e internacional. Ci. Inf., v. 27, n. 2, p. 134-140, 1998.

MEDEIROS, J. M. G. de; VITORIANO, M. A. V. A evolução da bibliometria e sua interdisciplinaridade na produção científica brasileira. RDBCI: Revista Digital de Biblioteconomia e Ciência da Informação, v. 13, n. 3, p. 491-503, set. 2015.

OLIVEIRA, T. As políticas científicas na era do conhecimento: uma análise de conjuntura sobre o ecossistema científico global. Perspectivas da Ciência da Informação, v. 24, n. 1, p. 191-215, 2019.

PEDRO, J. M. Traduzindo o debate: o uso da categoria gênero na pesquisa histórica. História, v. 24, n.1, p. 77-98, 2005.

PINTO, C. R. J. Uma história do feminismo no Brasil. São Paulo: Fundação Perseu Abramo, 2003.

ROCHA, P; M; WOITOWICZ, K. O processo de feminização do jornalismo: da invisibilidade às mudanças no mercado profissional. In: SEMINÁRIO INTERNACIONAL FAZENDO GÊNERO. Florianópolis, 2017. Anais [...].

RONSINI, V.; SILVA, R. C. Mulheres e telenovela: a recepção pela perspectiva das relações de gênero. E-Compós, v. 14, n. 1, set. 2011.

SARMENTO, R. Feminismos, mídia e internet. In: ENCONTRO NACIONAL DA NOVA REDE DE PESQUISAS EM FEMINISMOS E POLÍTICA. BRASÍLIA. Distrito Federal, 2018. Anais [...].

SARMENTO, R. Mídia, gênero e política: breve mapeamento de horizonte analíticos. Ação Midiática, v. 2, n. 5, p. 1-15, 2013.

SCOTT, J. Gênero: uma categoria útil de análise histórica. Educação \& Realidade, v. 20, n. 2, p. 71-99, jul./ dez. 1995.

SCOFIELD, T. H. P. Mídia e mulheres: um percurso compartilhado no território dos Estudos Culturais. Lumina, Juiz de Fora, v. 2, n. 1, p. 1-13, jul. 2008.

TOMAZETTI, T. Genealogias dissidentes: os estudos de gênero nas teses e dissertações em comunicação do Brasil (1972-2015). Tese (Doutorado em Comunicação e Informação) - Universidade Federal do Rio Grande do Sul, Porto Alegre, 2019. $201 \mathrm{f}$.

TOMAZETTI, T.; CORUJA, P. Relações de gênero nos estudos de recepção e consumo midiático: perspectivas de teses e dissertações em comunicação entre 2010 e 2015. Novos Olhares, v. 6, n. 1, p. 115-128, 2017.

ZIRBEL, I. Estudos feministas e estudos de gênero no Brasil: um debate. Dissertação (Mestrado em Sociologia Política) - Universidade Federal de Santa Catarina, Florianópolis, 2007. 212 f.

\section{Camilla Quesada Tavares}

Professora adjunta da graduação e do Programa de Pós-Graduação em Comunicação da Universidade Federal do Maranhão (UFMA/Imperatriz). Doutora em Comunicação pela Universidade Federal Fluminense(UFF), mestre em Ciências Sociais Aplicadas pela Universidade Estadual de Ponta Grossa (UEPG) e graduada em Comunicação Social - Jornalismo pela mesma instituição. Coordenadora 
do grupo de pesquisa Comunicação, Política e Sociedade (COPS/UFMA). Coordenadora da Imprensatriz - Empresa Júnior de Jornalismo (UFMA). E-mail: camilla.tavares8@gmail.com.

\section{Michele Goulart Massuchin}

Professora do Departamento de Comunicação (DECOM), do Programa de Pós-Graduação em Comunicação (PPGCOM) e do Programa de Pós-Graduação em Ciência Política (PPGCP) da Universidade Federal do Paraná (UFPR). Doutora em Ciência Política pela Universidade Federal de São Carlos (UFSCar). Faz parte do Grupo de Pesquisa em Comunicação, Política e Opinião Pública (da UFPR) e Grupo de Pesquisa em Comunicação, Política e Sociedade (da UFMA). E-mail: mimassuchin@gmail.com.

\section{Nayara Nascimento de Sousa}

Mestranda pelo Programa de Pós-Graduação em Comunicação da Universidade Federal do Maranhão (UFMA). Graduada em Comunicação Social - Jornalismo, também pela UFMA. Integrante do Grupo de Pesquisa em Comunicação, Política e Sociedade (UFMA). Os interesses de pesquisa têm como focos gênero, jornalismo e política. E-mail: nayara.nns@hotmail.com.

\section{Gabriela Almeida Silva}

Mestranda pelo Programa de Pós-Graduação em Comunicação da Universidade Federal do Maranhão (UFMA). Graduada em Comunicação Social - Jornalismo, também pela UFMA. Integrante do Grupo de Pesquisa em Comunicação, Política e Sociedade (UFMA). E-mail: gabrielaalmeida.gc@gmail.com.

Recebido em: 18.03.2020

Aprovado em: 18.02.2021

Este artigo é publicado em acesso aberto (Open Access) sob a licença Creative Commons Attribution Non-Commercial (CC-BY-NC), que permite uso, distribuição e reprodução em qualquer meio, sem restrições, desde que sem fins comerciais e que o trabalho original seja corretamente citado. 